\title{
Clinical Study \\ Effect of Low Dose Dexmedetomidine on Emergence Delirium and Recovery Profile following Sevoflurane Induction in Pediatric Cataract Surgeries
}

\author{
Babita Ghai, Divya Jain, Payal Coutinho, and Jyotsna Wig \\ Department of Anesthesia and Intensive Care, Post Graduate Institute of Medical Education and Research, Chandigarh, India \\ Correspondence should be addressed to Divya Jain; jaindivya77@rediffmail.com
}

Received 1 August 2015; Revised 7 October 2015; Accepted 12 October 2015

Academic Editor: Thomas Engelhardt

Copyright (c) 2015 Babita Ghai et al. This is an open access article distributed under the Creative Commons Attribution License, which permits unrestricted use, distribution, and reproduction in any medium, provided the original work is properly cited.

\begin{abstract}
This randomized trial was conducted to assess the efficacy and recovery profile of low dose intravenous dexmedetomidine in prevention of post-sevoflurane emergence delirium in children undergoing cataract surgery. Sixty-three children aged 1-6 years were included. Anesthesia was induced with sevoflurane and airway was maintained with LMA. They were randomized to group D 0.15 (received intravenous dexmedetomidine $0.15 \mu \mathrm{g} / \mathrm{kg}$ ), group D 0.3 (received dexmedetomidine $0.3 \mu \mathrm{g} / \mathrm{kg}$ ), or group NS (received normal saline). The incidence of emergence delirium, intraoperative haemodynamic variables, Aldrete scoring, pain scoring, rescue medication, and discharge time were recorded. Emergence delirium was significantly reduced in dexmedetomidine treated groups with incidence being $10 \%$ in group D 0.15 , none in group D 0.3 , and $35 \%$ in the NS group ( $p=0.002$ ). Significantly lower PAED scores were observed in D 0.15 and D 0.3 group compared to the NS group $(p=0.004)$. Discharge time was significantly prolonged in the NS group compared to D 0.15 and D 0.3 (45.1 $\mathrm{min} \pm 4.4$ versus $36.8 \mathrm{~min} \pm 3.8$ versus $34.4 \mathrm{~min} \pm 4.6), p<0.02$. Intravenous dexmedetomidine in low doses $(0.3$ and $0.15 \mu \mathrm{g} / \mathrm{kg})$ was found to be effective in reducing emergence delirium in children undergoing unilateral cataract surgery.
\end{abstract}

\section{Introduction}

Emergence delirium is often witnessed after sevoflurane anesthesia with an incidence of approximately $20 \%-60 \%[1$, 2]. It is characterized by mental disturbance consisting of hallucinations, delusions, and confusion manifested by moaning, restlessness, involuntary physical activity, and thrashing about in bed during the recovery from general anaesthesia [3]. While emergence delirium remains a poorly understood phenomenon, a variety of potential etiologies including pain, stressful induction, hypoxemia, rapid awakening in hostile environment, and physical stimulation (noise) have been implicated [4]. It carries a significant risk of bleeding from the site of surgery, psychological trauma to the parents, and delayed discharge of the patient from the postanesthesia care unit (PACU) [5].

Several drugs have been used to treat post-sevoflurane agitation which include propofol [6], midazolam [7, 8], ketamine [9], and alpha-2 agonist like clonidine [10] and dexmedetomidine [11-13].

Dexmedetomidine, an alpha-2 agonist, is a recent drug used to prevent post-sevoflurane agitation. However, due to the variation in the dose used in various studies, to date, there has been no consensus on the dose of DEX used for prevention of emergence agitation [11-13]. Doses of $0.5 \mu \mathrm{g} / \mathrm{kg}$ and above have been effectively used to reduce post-sevoflurane agitation but were associated with increased incidence of side effects such as reduction in heart rate, blood pressure, delayed emergence, and extubation [12].

Anxiety before and during induction of anesthesia has often been associated with an increased risk of postoperative negative behavioural changes apart from emergence delirium [7]; as a result, avoiding premedication drugs may not be desirable in the routine clinical practice. However, majority of the studies evaluated children without premedication and this made previous studies less realistic. 
In the literature, there is a considerable overlap in the terminologies of emergence delirium and agitation. Most of the previous studies have evaluated emergence agitation instead of emergence delirium, resulting in inconsistent and variable results.

Oral midazolam $0.5 \mathrm{mg} / \mathrm{kg}$ is routinely used as premedicant in our institution 20-30 minutes before surgery. We hypothesized that two lower doses of intravenous (IV), that is, $0.15 \mu \mathrm{g} / \mathrm{kg}$ and $0.3 \mu \mathrm{g} / \mathrm{kg}$, dexmedetomidine in conjunction with oral midazolam might be more effective than placebo in reducing the incidence of post-sevoflurane agitation in children undergoing elective cataract surgery.

We, therefore, aimed to study dexmedetomidine $0.15 \mu \mathrm{g} / \mathrm{kg}$ and $0.3 \mu \mathrm{g} / \mathrm{kg}$ in children premedicated with midazolam $(0.5 \mathrm{mg} / \mathrm{kg})$ using a validated scale.

\section{Materials and Methods}

This study was conducted in the ophthalmic centre of a tertiary care institute from July 2010 to December 2011. After obtaining the local ethical committee approval and written informed consent from parents/legal guardian of the children, 63 American Society of Anesthesiologists physical status I and II children, aged between 1 and 6 years, undergoing elective cataract surgery were included in the randomized, controlled, double-blind study. Children with a history of allergy to anesthetic agents, seizures, mental retardation, endocrine disorder, psychiatric disorder, and emergency procedure or history of previous episode of emergence delirium or who refused to take premedication were excluded from the study.

All children were kept fasting according to the NPO guidelines. They were premedicated with oral midazolam syrup $0.5 \mathrm{mg} / \mathrm{kg}$, 30 minutes before induction of anaesthesia. A 4-point scale for parental separation score and induction score was noted (Appendices A and B) [14] prior to shifting the child to the operating room. Inside the operating room, routine anesthesia monitoring was established while taking care not to stimulate the child. Anesthesia was induced with $5-8 \%$ sevoflurane and $100 \%$ oxygen. After induction of anesthesia, venous cannulation was established and once the adequate depth of anesthesia (MAC $=2.0)$ was ensured, laryngeal mask airway (LMA) of appropriate size was inserted for the maintenance of the airway.

Anesthesia was maintained with $1-1.5 \%$ of sevoflurane with $60 \%$ nitrous oxide in oxygen with spontaneous breathing. Patients were randomized into 3 groups using a computer based randomization chart. Group NS $(n=20)$ received normal saline, group D $0.15(n=20)$ received IV dexmedetomidine $0.15 \mu \mathrm{g} / \mathrm{kg}$, and group D $0.3(n=23)$ received IV dexmedetomidine $0.3 \mu \mathrm{g} / \mathrm{kg}$ and results of randomization were concealed in opaque envelopes. The study drug was prepared by an independent anesthetist not participating in the study after opening a sealed envelope. The anesthetist, surgeon, and observer were all blinded. The master code was held by a person not participating in the study. All the study drugs were diluted in $5 \mathrm{~mL}$ of normal saline and administered over 5-minute duration by a blinded anesthetist. Analgesia was given in the form of sub-Tenon block with $0.1 \mathrm{~mL} / \mathrm{kg}$ of $0.5 \%$ bupivacaine, administered by the surgeon, and supplemented with IV paracetamol $15 \mathrm{mg} / \mathrm{kg}$. Ventilation was assisted if end-tidal carbon dioxide (EtCO2) levels increased above $45 \mathrm{~mm}$ of $\mathrm{Hg}$. At the end of the procedure, LMA was removed and sevoflurane was switched off after the removal of the LMA. The child was shifted to a calm, quite, mildly illuminated postanesthesia care unit (PACU) recovery room with one of the parents who was allowed to stay in PACU with the child.

All children were monitored continuously until their discharge from the PACU and oxygen saturation, heart rate, and noninvasive blood pressure were recorded every 15 minutes. The same trained independent PACU nurse, blinded to the anaesthetic technique, repeatedly recorded the degree of agitation every $15 \mathrm{~min}$ up to 1 hour after admission. All assessors were trained and experienced in the application of the assessment scales. The state of agitation was recorded using Pediatric Anaesthetic Emergence Delirium (PAED) scale (Appendix C) $[14,15]$ and score 10/20 was considered as delirium. If agitation was present, the first measure was to console the child by parent; if the child is inconsolable for 5 minutes, rescue medication with fentanyl $0.5 \mu \mathrm{g} / \mathrm{kg}$ was used. Postoperative pain was assessed using Face, Legs, Activity, Cry, Consolability (FLACC) pain scale (0-10 score range) (Appendix D) [16]. If FLACC score was more than five, intravenous fentanyl $0.5 \mu \mathrm{g} / \mathrm{kg}$ was given [16]. The pain score of $>5$ was considered as a cut-off point for rescue medication with fentanyl. Modified Aldrete scores (Appendix E) were recorded during PACU stay [17]. Children were considered ready for discharge from the PACU with an Aldrete score $\geq 9$. Primary outcome of the study was the incidence of postoperative delirium as measured with PAED score. Secondary end points included intraoperative haemodynamic variables, Aldrete scoring, pain scoring, rescue medication, and discharge time.

The sample size was based on a pilot study. Assuming the incidence of emergence delirium to be $40 \%$, reduction to $8 \%$ ( $80 \%$ reduction) was considered clinically significant justifying addition of dexmedetomidine. Based on these assumptions, with $\alpha$ error of 0.05 (one-sided) and power of $80 \%, 18$ patients were required in each group. However, to compensate for possible dropouts, 63 patients were enrolled.

SPSS (SPSS Inc., Chicago, IL, version 16.0 for Windows) was used for statistical analysis. Demographic data (continuous variable) of the 3 groups were expressed as mean \pm SD and were analysed by ANOVA. Nonparametric data (scores) were expressed as median \pm IQR and analysed using the Kruskal Wallis test. If found significant, Mann-Whitney test was used for pairwise comparison. Serial changes in intraoperative parameters (heart rate, systolic BP, diastolic $\mathrm{BP}$, mean $\mathrm{BP}, \mathrm{EtCO} 2$, and respiratory rate) and postoperative heart rate and postoperative $\mathrm{BP}$ were analysed using twoway ANOVA. In this analysis, qualitative and quantitative variables were recorded repeatedly over time for each subject. 
TABLE 1: Demographic and baseline variables.

\begin{tabular}{|c|c|c|c|c|}
\hline & $\mathrm{D} 0.3(n=23)$ & $\mathrm{D} 0.15(n=20)$ & NS $(n=20)$ & $p$ value \\
\hline Age (yrs) & $4.22 \pm 1.71$ & $3.23 \pm 1.99$ & $4.18 \pm 1.92$ & NS \\
\hline Gender $(\mathrm{M} / \mathrm{F})$ & $10 / 13$ & $14 / 6$ & $15 / 5$ & NS \\
\hline Weight $(\mathrm{kg})$ & $16.11 \pm 6.2$ & $13.13 \pm 5.63$ & $17.5 \pm 6.91$ & NS \\
\hline Duration of anaesthesia (min) & $24.35 \pm 5.7$ & $30 \pm 8.7$ & $24.25 \pm 4.9$ & NS \\
\hline Parental separation score & $1.4(3)$ & $1.9(3)$ & $1.65(4)$ & $0.13^{\#}$ \\
\hline Induction score & $1.15(3)$ & $1.4(3)$ & $1.5(2)$ & $0.77^{\#}$ \\
\hline
\end{tabular}

${ }^{\#} p<0.05$, groups D 0.3 and D 0.15 compared to NS. Group D 0.3: intravenous dexmedetomidine $0.3 \mu \mathrm{g} / \mathrm{kg}$. Group D 0.15: intravenous dexmedetomidine $0.15 \mu \mathrm{g} / \mathrm{kg}$. Group NS: intravenous normal saline. Data are presented as mean \pm SD except when stated otherwise.

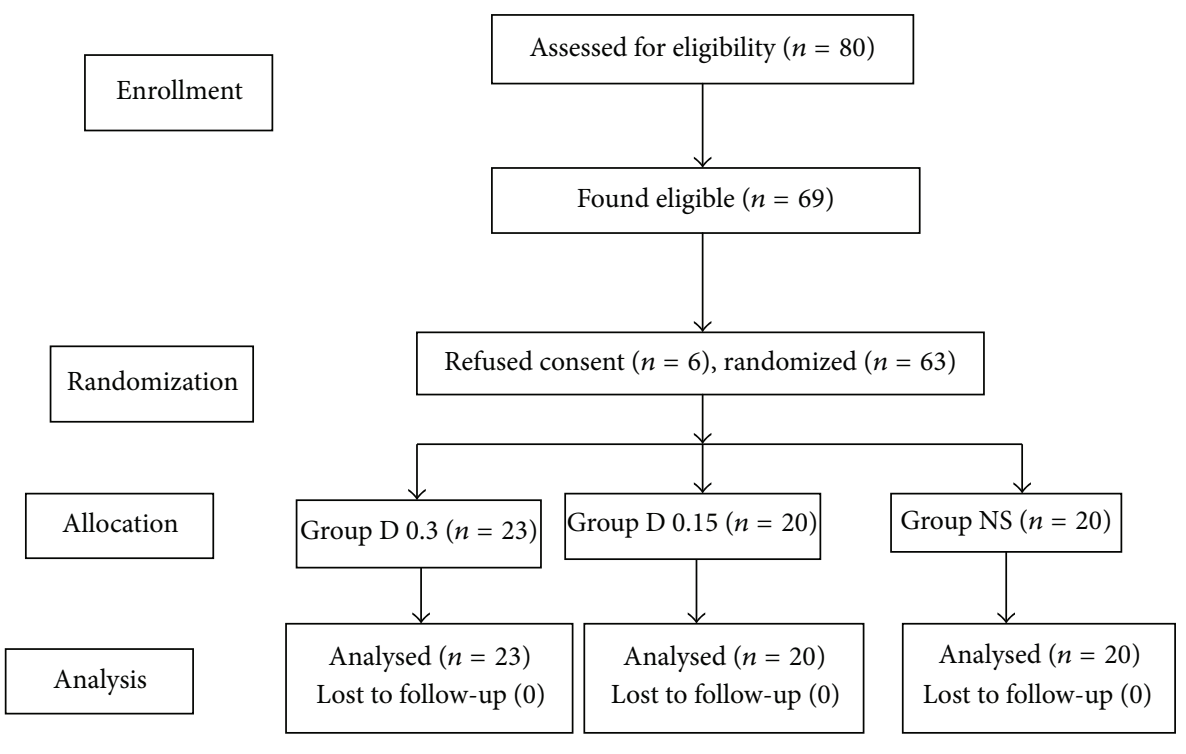

FIGURE 1: Consort flowchart.

Paired Student's $t$-test was used to compare baseline variables at different time interval. A $p$ value of $<0.05$ was taken to be significant.

Data was tested for normality using Kolmogorov test, for homogeneity of between-groups variance using Levene's test, and for sphericity using the Mauchly test. If the Mauchly test was significant, indicating violation of assumption of sphericity, we used Greenhouse Geisser test within subject effects.

\section{Results}

Out of the sixty-nine children enrolled in the study, guardians of six patients refused to give consent; therefore, sixty-three children completed the study and were analysed (Figure 1). Children in the three groups were comparable with respect to their age, gender, weight, duration of anesthesia, preoperative parental separation scores, and induction scores (Table 1).

Seven children (35\%) in the normal saline group developed clinically significant emergence delirium with PAED score $\geq 10$. The incidence was significantly greater than that encountered in the dexmedetomidine groups ( 2 of the 20 patients in group D 0.15 , but none in group D 0.3 developed PAED score $\geq 10$ ). The PAED scale score for the first 15 minutes postoperatively was significantly different among the three groups ( $p<0.05$, Kruskal Wallis) (Table 3 ). Pairwise comparison revealed significantly lower PAED scores in groups D 0.3 and D 0.15 compared to group NS in the first fifteen minutes postoperatively ( $p<0.05$, Mann-Whitney). However, scores were comparable between groups D 0.3 and D 0.15. After $15 \mathrm{~min}$ in PACU, the PAED scale scoring was comparable in all the three groups $(p>0.05$, MannWhitney).

No differences were found between the study groups with respect to pain and no patient in any of these groups attained pain score $>5$ requiring rescue medication (Table 2 ). However, the rescue medication was given in $35 \%$ of patients in the NS group and $10 \%$ of patients in the D 0.15 group for PAED score $\geq 10 / 20$ as these were refractory to the parental counselling. Time to meet discharge was comparable between group D 0.3 (34.4 min \pm 4.6) and group D 0.15 (36.8 min \pm $3.8), p>0.05$. However, the discharge time was significantly longer in group NS compared to D 0.15 and D $0.3, p=0.029$.

No significant reduction of heart rate, blood pressure, respiratory rate, and saturation was noted in the three groups. 
TABLE 2: Postoperative variables. Values are median (IQR).

\begin{tabular}{|c|c|c|c|c|}
\hline & $\mathrm{D} 0.3(n=23)$ & $\mathrm{D} 0.15(n=20)$ & NS $(n=20)$ & $p$ value \\
\hline PAED scale $\geq 10$ & $0(0 \%)$ & $2(10 \%)$ & $7(35 \%)$ & $0.002^{\#}$ \\
\hline Pain score in PACU (median (range)) & $2(0-4)$ & $3(0-5)$ & $3(0-5)$ & NS \\
\hline Discharge time (minutes), mean $\pm \mathrm{SD}$ & $34.4 \pm 4.6$ & $36.8 \pm 3.8$ & $45.1 \pm 4.48$ & $<0.05^{\#}$ \\
\hline
\end{tabular}

${ }^{\#} p<0.05$.

TABLE 3: Postoperative pediatric agitation emergence scale (median (IQR)).

\begin{tabular}{lcccc}
\hline Time & $\mathrm{D} 0.3(n=23)$ & $\mathrm{D} 0.15(n=20)$ & $\mathrm{NS}(n=20)$ & $p$ value \\
\hline $0 \mathrm{~min}$ & $1(6)$ & $0(4)$ & $7(9)$ & $0.004^{\#}$ \\
$15 \mathrm{~min}$ & $0(4)$ & $0(4)$ & $7(10)$ & $0.005^{\#}$ \\
$30 \mathrm{~min}$ & $0(3)$ & $0(3)$ & $4(9)$ & 0.103 \\
$45 \mathrm{~min}$ & $0(3)$ & $0(3)$ & $0.5(6)$ & 0.558 \\
$60 \mathrm{~min}$ & $0(3)$ & $0(3)$ & $0(5)$ & 0.822 \\
\hline
\end{tabular}

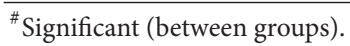

None of the children developed bradycardia, hypotension, or desaturation throughout the study period. Vomiting was observed in 2 children, 1 each in groups D 0.15 and NS in postoperative period which responded to IV ondansetron.

\section{Discussion}

The results of our study suggest that intravenous dexmedetomidine $(0.3 \mu \mathrm{g} / \mathrm{kg})$ effectively reduces emergence agitation in children premedicated with oral midazolam and undergoing cataract surgery.

The incidence of emergence delirium in the control group in our study was 35\% in accordance with Ghai et al. [10] that reported an incidence of emergence delirium of $27.5 \%$ in the control group in pediatric cataract surgery.

There is no clear definition of emergence delirium and often it has been used interchangeably with emergence agitation (EA). The two have been defined independently by Sikich and Lerman who defined emergence delirium (ED) as "a disturbance in a child's awareness of attention to his/her environment with disorientation and perceptual alterations including hypersensitivity to stimuli and hyperactive motor behaviour in the immediate postanesthesia period." This primarily cognitive disturbance needs to be distinguished from EA, where pain, previous underlying anxiety, and other unspecified factors contribute to the restlessness of the child in the postoperative period [18-20].

In our study, an attempt to eliminate this confounding factor was made with an effective sub-Tenon block with local anesthetic and intravenous paracetamol supplementation, which has been reported to provide adequate analgesia in pediatric cataract surgeries, and none of our patients required intraoperative rescue medication for inappropriate pain therapy.

Although the use of dexmedetomidine to prevent and treat post-sevoflurane agitation [11-13] has been documented in the literature, the evaluation of its effect on emergence delirium which now forms a distinct entity remains underevaluated. Exact mechanism of $\alpha_{2}$ agonist in prevention of emergence delirium is yet to be elucidated. The proposed mechanism is a reduction in noradrenergic output from locus ceruleus, thereby facilitating the firing of inhibitory neurons such as Gamma aminobutyric acid system [20].

Various studies have used variable doses of dexmedetomidine for prevention of postoperative negative behaviour [11-13].

Shukry et al. studied the effects of a continuous perioperative infusion of $0.2 \mathrm{microg} \cdot \mathrm{kg}(-1) \cdot \mathrm{h}(-1)$ dexmedetomidine on the incidence of ED in 50 children aged 1-10 years scheduled for sevoflurane-based GA. They found significant reduction in the incidence of ED with dexmedetomidine $(p=0.036)$. Additionally, the number of episodes of ED was lower with dexmedetomidine $(p<0.017)$. However, the pain scores, times to extubation, and discharge from PACU were the same $[2]$.

Patel et al. [11] evaluated postoperative emergence delirium as well as analgesic sparing effect of $2 \mathrm{mcg} / \mathrm{kg}$ dexmedetomidine, compared to $1 \mathrm{mcg} / \mathrm{kg}$ fentanyl in children undergoing adenotonsillectomy. Emergence delirium was evaluated by PAED scale as well as Cole scale [21]. The results demonstrated a significant reduction in emergence agitation in dexmedetomidine treated group (incidence of EA, 18\% compared to $45.9 \%$ in fentanyl). However, there was a significant drop in heart rate as well as blood pressure in dexmedetomidine treated group compared to fentanyl $(p<0.001)$.

However, on the other hand, Bong et al. failed to demonstrate any effect of $0.3 \mathrm{mcg} / \mathrm{kg}$ dexmedetomidine on the incidence of emergence delirium in children undergoing general anaesthesia for magnetic resonance imaging.

In our study, we used $0.3 \mathrm{mcg} / \mathrm{kg}$ and $0.15 \mathrm{mcg} / \mathrm{kg}$ doses of dexmedetomidine in midazolam premedicated children aged 1-6 years undergoing cataract surgery. The children in the age group of 1-6 years have the highest incidence of emergence agitation and delirium $[4,5,7]$. Notably, in our study, emergence delirium reduced from $35 \%$ in NS group to $0 \%$ and $10 \%$ in groups D 0.3 and D 0.15 , respectively. This is in contrast to the study by Bong and $\mathrm{Ng}$ and Ibacache et al. $[13,16]$ using similar doses. The difference in results could be attributed to the lack of premedication and difference in the nature of procedures done in the abovementioned trials. Midazolam premedication is routinely used in our setup for children undergoing cataract surgery. Preoperative anxiety results in restless recovery $[11,22]$. Midazolam premedication decreases preoperative anxiety and calms the child, thus facilitating parental separation. It is also reported to decrease 
emergence agitation following sevoflurane anesthesia with no delay in discharge [22]. In contrast, other studies have shown no effect of midazolam premedication on reduction of emergence agitation after sevoflurane anesthesia [23]. Aouad and Nasr [24] speculated that midazolam, a short acting premedicant, may result in residual effect at the end of a short procedure and decrease the incidence of EA, while the serum level might be too low to sedate a child after longer procedures. As cataract surgery is a short procedure, we assume a residual effect of midazolam in reduction of agitation.

Dexmedetomidine $(0.15$ and $0.3 \mu \mathrm{g} / \mathrm{kg})$ was associated with shorter discharge time compared to NS group. This could be due to greater number of children receiving rescue medication in the form of intravenous fentanyl postoperatively in the NS group (35\% compared to $10 \%$ and $0 \%$ in groups D 0.3 and D 0.15 , resp.). Our results are contrary to the meta-analysis which showed extended discharge time with dexmedetomidine compared to the placebo [25]. The eight randomized trials evaluated in the meta-analysis had used comparatively higher doses of dexmedetomidine or a bolus injection followed by an infusion dose, which could be a reason for the difference in the results.

In our study, we used the PAED scale, the only validated scale for rating emergence agitation, in our study. The investigators who developed the PAED scale assessed children 10 min after awakening (child remained awakened thereafter). This was a problem in our study in early stages as children who were asleep were receiving a rating of 4 on the first 3 items of the PAED scale (i.e., they were not able to make eye contact, they were not aware of the surroundings, and their actions were not purposeful) Therefore, we had to modify the scoring on the scale and rate these items as zero. It is obvious that children who were asleep were not agitated. Similar observation was reported by Patel et al. [11] in their study. We used PAED score $\geq 10$ as the indicator of agitation. A score of $\geq 10$ on the PAED scale has been defined as the best discriminator between presence and absence of clinical agitation as reported by Bong and $\mathrm{Ng}$ [16].

Rapid awakening in a hostile environment might frighten the children and may provoke agitation. In order to eliminate this, we allowed parental presence in a quiet and warm postanesthesia care unit.

It is difficult to completely discriminate between painrelated agitated behavior and emergence delirium in nonverbal and preschool children as there is some overlap of categories in scales assessing pain and emergence delirium. Lack of evaluation of the correlation between PAED and FLACC score can be taken as a shortcoming of our study. However, as the pain scores were comparable in all the three study groups and none of our patients required intraoperative rescue medication for inappropriate pain therapy, the bias due to this seems unlikely.

In conclusion, intravenous dexmedetomidine $0.3 \mu \mathrm{g} / \mathrm{kg}$ is effective for reducing agitation after sevoflurane anesthesia in children premedicated with $0.5 \mathrm{mg} / \mathrm{kg}$ of midazolam undergoing cataract surgery without causing adverse side effects such as increased sedation, hypotension, bradycardia, or delayed discharge. Intravenous dexmedetomidine $0.15 \mu \mathrm{g} / \mathrm{kg}$
TABle 4: Pediatric Anaesthetic Emergence Delirium (PAED) scale.

\begin{tabular}{lc}
\hline & Score \\
\hline The child makes eye contact with the caregiver & $4=$ not at all \\
\hline The child's actions are purposeful & $3=$ just a little \\
\hline The child is aware of his/her surroundings & $2=$ quite a bit \\
& $1=$ very much \\
& $0=$ extremely \\
\hline The child is restless & $0=$ not at all \\
\hline & $1=$ just a little \\
The child is inconsolable & $2=$ quite a bit \\
& $3=$ very much \\
& $4=$ extremely \\
\hline
\end{tabular}

Minimum score 0 and maximum score 20. The degree of emergence delirium increases directly with increasing score.

was also effective with no delay in discharge time; however, it did not completely eliminate agitation.

\section{Appendices}

\section{A. Parental Separation Score}

Parental separation score is as follows:

(1) Asleep.

(2) Good separation; awake; calm.

(3) Awake; anxious; can be easily reassured.

(4) Crying; cannot be reassured.

\section{B. Induction Score}

Induction score is as follows:

(1) Excellent; asleep; calm; awake; cooperative; accepting the mask.

(2) Slight fear but can be reassured easily.

(3) Moderate fear and reassured with difficulty.

(4) Crying; needs restraint.

\section{Pediatric Anaesthetic Emergence Delirium (PAED) Scale}

See Table 4.

\section{FLACC Score}

See Table 5.

\section{E. Modified Aldrete Score}

See Table 6. 
TABLE 5: FLACC score.

\begin{tabular}{|c|c|c|c|}
\hline Criteria & Score 0 & Score 1 & Score 2 \\
\hline Face & $\begin{array}{l}\text { No particular expression } \\
\text { or smile }\end{array}$ & $\begin{array}{l}\text { Occasional grimace or frown; } \\
\text { withdrawn; uninterested }\end{array}$ & $\begin{array}{c}\text { Frequent to constant } \\
\text { quivering chin; clenched jaw }\end{array}$ \\
\hline Legs & $\begin{array}{l}\text { Normal position or } \\
\text { relaxed }\end{array}$ & Uneasy; restless; tense & Kicking or legs drawn up \\
\hline Activity & $\begin{array}{l}\text { Lying quietly; normal } \\
\text { position; moves easily }\end{array}$ & $\begin{array}{c}\text { Squirming; shifting back and forth; } \\
\text { tense }\end{array}$ & Arched; rigid; or jerking \\
\hline Cry & No cry (awake or asleep) & $\begin{array}{c}\text { Moans or whimpers; occasional } \\
\text { complaint }\end{array}$ & $\begin{array}{l}\text { Crying steadily; screams or } \\
\text { sobs; frequent complaints }\end{array}$ \\
\hline Consolability & Content, relaxed & $\begin{array}{c}\text { Reassured by occasional touching, } \\
\text { hugging, or being talked to; } \\
\text { distractible }\end{array}$ & Difficult to console or comfort \\
\hline
\end{tabular}

Minimum score 0 and maximum score 10. Intensity of pain increases with increase in score.

TABLE 6: Modified Aldrete score.

(1) Activity

(2) Respiration

(3) Circulation

(4) Consciousness

(5) $\mathrm{O}_{2}$ saturation

(6) Dressing

(7) Pain

(8) Ambulation

(9) Fasting/feeding

(10) Urine output
Ability to move 4 extremities voluntarily or on command 2

Ability to move 2 extremities voluntarily or on command 1

Unable to move extremities voluntarily or on command

Able to breathe deeply or cough freely

Dyspnea, limited breathing, or tachypnea

Apneic or on mechanical ventilator

$\mathrm{BP} \pm 20 \%$ of preanaesthetic level

$\mathrm{BP} \pm 20$ to $49 \%$ of preanaesthetic level

$\mathrm{BP} \pm 50 \%$ of preanaesthetic level

Fully awake

Arousable on calling

Not responding

Able to maintain $>92 \%$ on room air

Needs $\mathrm{O}_{2}$ inhalation to maintain $>90 \%$

$\mathrm{O}_{2}$ saturation $<90 \%$ even with $\mathrm{O}_{2}$ supplementation

Dry and clean

Wet but marked and not increasing

Growing areas of wetness

Pain-free

Mild pain handled by oral medication

Severe pain requiring parental medication

Able to stand up and walk straight*

Vertigo when feeling erect

Dizziness when supine

Able to drink fluids

Nauseated

Nausea and vomiting

Has voided

Unable to void but comfortable

Unable to void and uncomfortable

Note: total score must be at least 18 in order for the patient to be discharged home. 


\section{Conflict of Interests}

The authors declare that there is no conflict of interests regarding the publication of this paper.

\section{References}

[1] S. Sethi, B. Ghai, J. Ram, and J. Wig, "Postoperative emergence delirium in pediatric patients undergoing cataract surgery-a comparison of desflurane and sevoflurane," Paediatric Anaesthesia, vol. 23, no. 12, pp. 1131-1137, 2013.

[2] M. Shukry, M. C. Clyde, P. L. Kalarickal, and U. Ramadhyani, "Does dexmedetomidine prevent emergence delirium in children after sevoflurane-based general anesthesia?" Paediatric Anaesthesia, vol. 15, no. 12, pp. 1098-1104, 2005.

[3] N. Sikich and J. Lerman, "Development and psychometric evaluation of the paediatric anesthesia emergence delirium scale," Anesthesiology, vol. 100, no. 5, pp. 1138-1145, 2004.

[4] F. Veyckemans, "Excitation and delirium during sevoflurane anesthesia in pediatric patients," Minerva Anestesiologica, vol. 68, no. 5, pp. 402-405, 2002.

[5] J. Aono, W. Ueda, K. Mamiya, E. Takimoto, and M. Manabe, "Greater incidence of delirium during recovery from sevoflurane anesthesia in preschool boys," Anesthesiology, vol. 87, no. 6, pp. 1298-1300, 1997.

[6] I. Abu-Shahwan, "Effect of propofol on emergence behavior in children after sevoflurane general anesthesia," Paediatric Anaesthesia, vol. 18, no. 1, pp. 55-59, 2008.

[7] Z. N. Kain, A. A. Caldwell-Andrews, I. Maranets et al., "Preoperative anxiety and emergence delirium and postoperative maladaptive behaviors," Anesthesia and Analgesia, vol. 99, no. 6, pp. 1648-1654, 2004.

[8] S. L. Lapin, S. M. Auden, L. J. Goldsmith, and A.-M. Reynolds, "Effects of sevoflurane anaesthesia on recovery in children: a comparison with halothane," Paediatric Anaesthesia, vol. 9, no. 4, pp. 299-304, 1999.

[9] J.-Y. Chen, J.-E. Jia, T.-J. Liu, M.-J. Qin, and W.-X. Li, "Comparison of the effects of dexmedetomidine, ketamine, and placebo on emergence agitation after strabismus surgery in children," Canadian Journal of Anesthesia, vol. 60, no. 4, pp. 385-392, 2013.

[10] B. Ghai, J. Ram, S. Chauhan, and J. Wig, "Effects of clonidine on recovery after sevoflurane anaesthesia in children undergoing cataract surgery," Anaesthesia and Intensive Care, vol. 38, no. 3, pp. 530-537, 2010.

[11] A. Patel, M. Davidson, M. C. J. Tran et al., "Dexmedetomidine infusion for analgesia and prevention of emergence agitation in children with obstructive sleep apnea syndrome undergoing tonsillectomy and adenoidectomy," Anesthesia and Analgesia, vol. 111, no. 4, pp. 1004-1010, 2010.

[12] G. Guler, A. Akin, Z. Tosun, S. Ors, A. Esmaoglu, and A. Boyaci, "Single-dose dexmedetomidine reduces agitation and provides smooth extubation after pediatric adenotonsillectomy," Paediatric Anaesthesia, vol. 15, no. 9, pp. 762-766, 2005.

[13] M. E. Ibacache, H. R. Muñoz, V. Brandes, and A. L. Morales, "Single-dose dexmedetomidine reduces agitation after sevoflurane anesthesia in children," Anesthesia \& Analgesia, vol. 98, no. 1, pp. 60-63, 2004.

[14] B. Ghai, R. P. Grandhe, A. Kumar, and P. Chari, "Comparative evaluation of midazolam and ketamine with midazolam alone as oral premedication," Paediatric Anaesthesia, vol. 15, no. 7, pp. 554-559, 2005.
[15] N. Sikich and J. Lerman, "Development and psychometric evaluation of the pediatric anesthesia emergence delirium scale," Anesthesiology, vol. 100, no. 5, pp. 1138-1145, 2004.

[16] C. L. Bong and A. S. B. Ng, "Evaluation of emergence delirium in Asian children using the Pediatric Anesthesia Emergence Delirium Scale," Paediatric Anaesthesia, vol. 19, no. 6, pp. 593600, 2009.

[17] S. Merkel, "The FLACC: a behavioural scale for scoring postoperative pain in young children," Pediatric Nursing, vol. 23, pp. 293-297, 1997.

[18] D. Pawar, "Common post-operative complications in children," Indian Journal of Anaesthesia, vol. 56, no. 5, pp. 496-501, 2012.

[19] S. Malarbi, R. Stargatt, K. Howard, and A. Davidson, "Characterizing the behavior of children emerging with delirium from general anesthesia," Paediatric Anaesthesia, vol. 21, no. 9, pp. 942-950, 2011.

[20] L. Bortone, G. Bertolizio, T. Engelhardt, G. Frawley, M. Somaini, and P. M. Ingelmo, "The effect of fentanyl and clonidine on early postoperative negative behavior in children: a doubleblind placebo controlled trial," Paediatric Anaesthesia, vol. 24, no. 6, pp. 614-619, 2014.

[21] J. W. Cole, D. J. Murray, J. D. McAllister, and G. E. Hirshberg, "Emergence behaviour in children: defining the incidence of excitement and agitation following anaesthesia," Paediatric Anaesthesia, vol. 12, no. 5, pp. 442-447, 2002.

[22] Y.-P. Ko, C.-J. Huang, Y.-C. Hung et al., "Premedication with low-dose oral midazolam reduces the incidence and severity of emergence agitation in pediatric patients following sevoflurane anesthesia," Acta Anaesthesiologica Sinica, vol. 39, no. 4, pp. 169 $177,2001$.

[23] B. C. Weldon, M. Bell, and T. Craddock, "The effect of caudal analgesia on emergence agitation in children after sevoflurane versus halothane anesthesia," Anesthesia and Analgesia, vol. 98, no. 2, pp. 321-326, 2004.

[24] M. T. Aouad and V. G. Nasr, "Emergence agitation in children: an update," Current Opinion in Anaesthesiology, vol. 18, no. 6, pp. 614-619, 2005.

[25] J.-H. Chen, Y.-Q. Yu, H.-J. Chu, H. He, C. Ya, and Z.-P. Dai, "Effects of dexmedetomidine on postoperative recovery profile after sevoflurane anesthesia in pediatric patients: a metaanalysis," Journal of Anesthesia and Clinical Research, vol. 4, no. 11, article 369, 2013. 


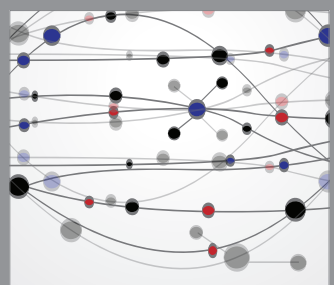

The Scientific World Journal
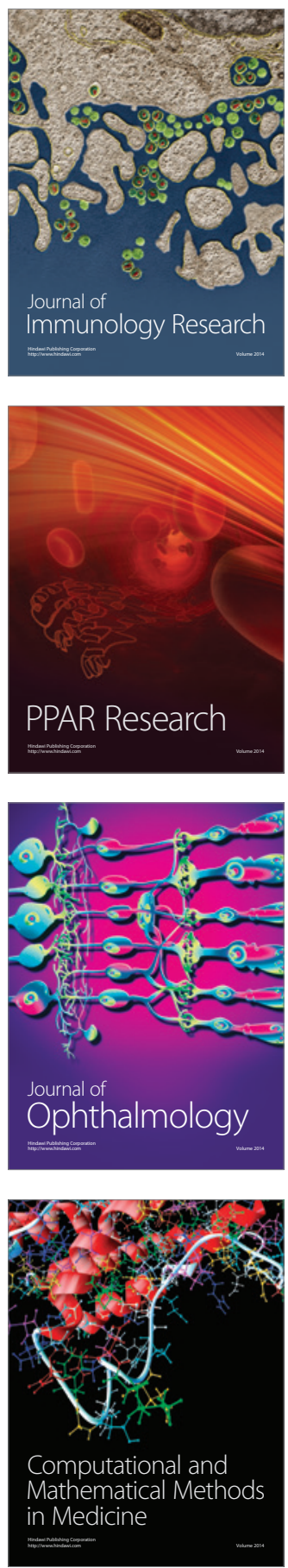

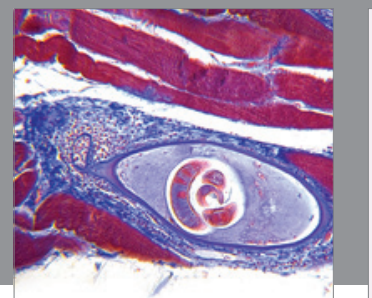

Gastroenterology

Research and Practice
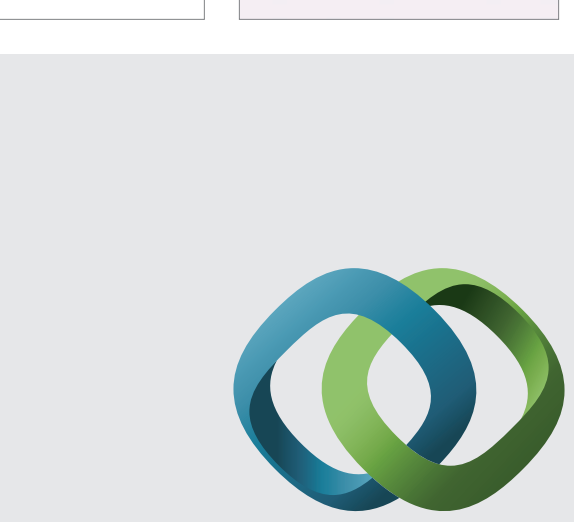

\section{Hindawi}

Submit your manuscripts at

http://www.hindawi.com
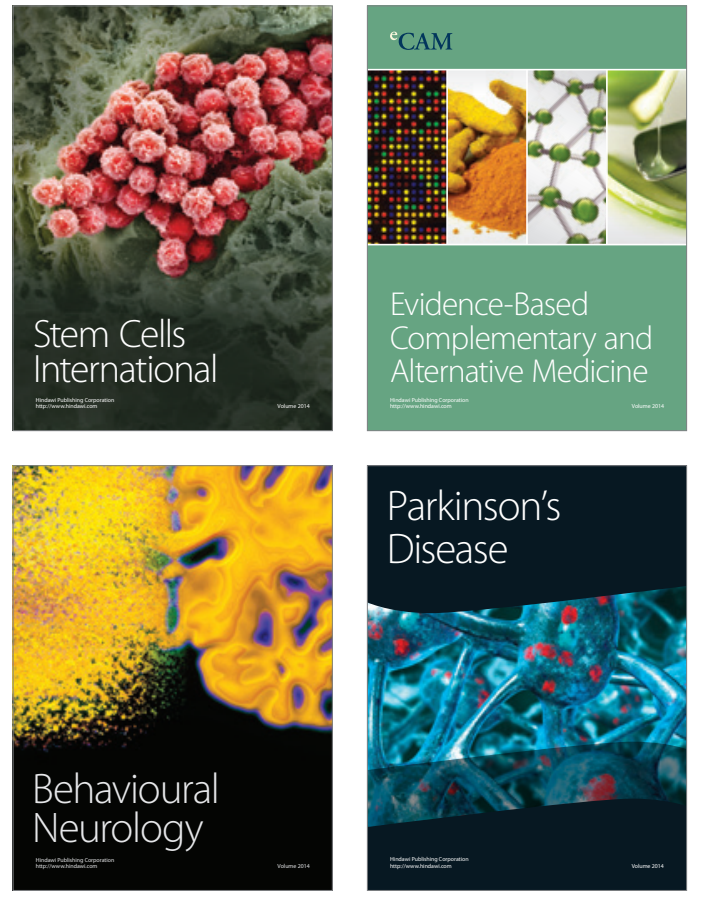
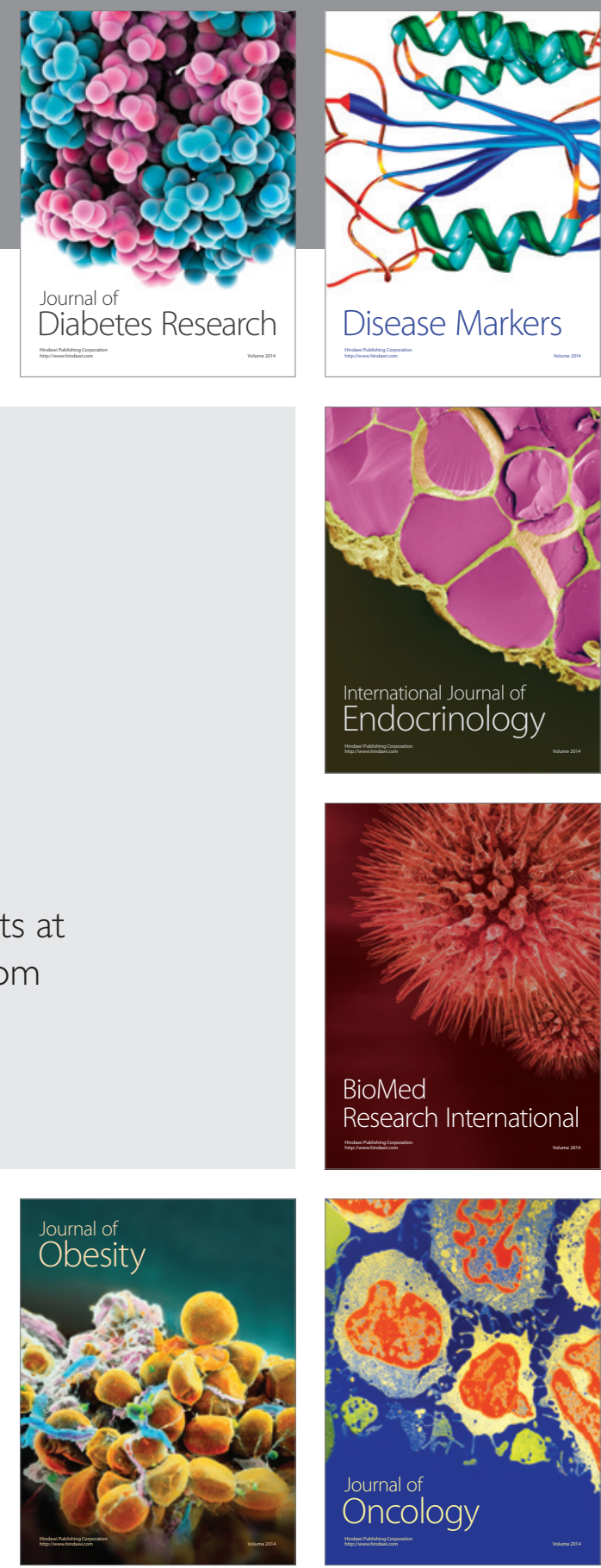

Disease Markers
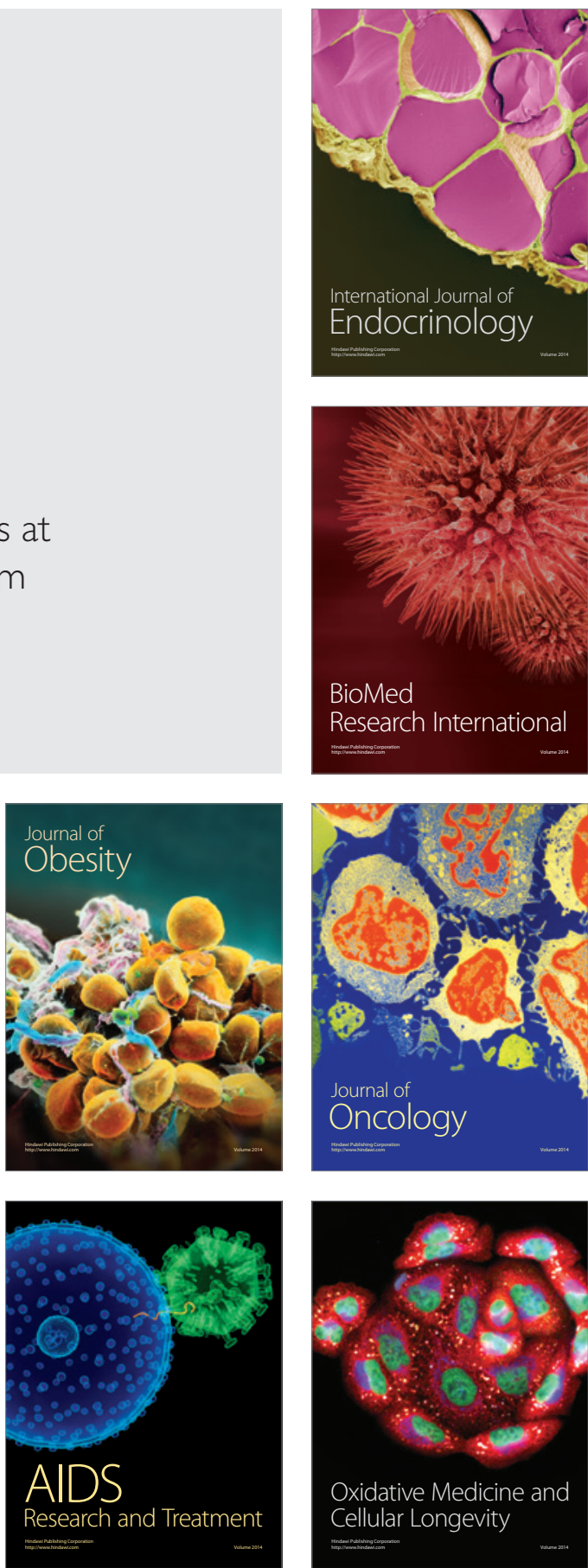